\title{
Study on Flipped Classroom Teaching of College English under New Media Environment
}

\author{
Chang Liu \\ Liaoning University of International Business and Economics, Dalian, Liaoning, 116052, China
}

Keywords: New media, English, Flipped classroom, Teaching.

\begin{abstract}
Under new media environment, new media technology and educational resources are connected and combined optimally so that education can benefit from internet media resources. On this basis, numerous new teaching modes and methods are generated. The flipped classroom is one of very important teaching methods. The flipped classroom applies new media video resources, and provides massive teaching resources and very sufficient activity time. It can create favorable English learning environment and achieve the purpose of learning knowledge in order to apply it. Based on the overview of flipped classroom, distinct characteristics of flipped classroom are analyzed, and the necessity of flipped classroom teaching of College English under new media environment is stated. Besides, several countermeasures on flipped classroom teaching of College English under new media environment are proposed.
\end{abstract}

\section{Introduction}

New media mainly refers to a kind of communication form. It applies modern network technology, internet and satellite communication and comprehensively provides information service for users through computer, mobile phone and other terminals. Traditional college new media teaching fails to achieve face-to-face exchange between students and teachers, but the major purpose of language learning is to communicate and exchange. It is more difficult to get rid of communication subject people. The flipped classroom exactly combines superior new media resources and practical language environment. It not just can achieve the overall process of effective input and output advocated by constructivism, but also practically changes the teaching form of classroom teaching where the teacher plays the leading role. The flipped classroom teaching of College English under new media environment can let college students learn anytime and anywhere via various terminals, overall grasp information and improve independently inquiry ability. Teachers can continuously promote English teaching effect, and really implement learner-centered teaching mode.

\section{Overview of flipped classroom}

The flipped classroom is also called inverted classroom. In the flipped classroom, the teacher combines key and difficult points with some new knowledge to form the video with strong practicability. Students can fully apply spare time to view the video and independently learn new courses. Then, they finish the required tests as per the video to internalize new knowledge. Next, students participate in class exchange and interaction with doubts so as to achieve the solid mastery of new knowledge. In this way, students can practically complete the whole process of course learning. The flipped classroom derived from two teachers of a senior high school in US. Since Salman Khan promoted it actively in 2011, the teaching mode has been mastered by more teachers. Since then, educational circles in the world have joined in the topic research. But, there are just a few researches on flipped classroom in China. It needs to further studied and applied. 


\section{Distinct characteristics of flipped classroom}

Firstly, teacher role change is achieved. Flipped teaching can change the inherent role of teachers. In previous teaching, teachers are in the status of imparting knowledge and solving doubts, actively teach and communicate new knowledge. Teachers are completely teachers and managers of classroom teaching. After flipped classroom is introduced, the role of teachers is repositioned. They are no longer the dominators and managers of teaching, but guiders. In the previous teaching, students are in the passive status. In this teaching mode, the roles of both teachers and students change significantly. Under active guidance of teachers, students can carry out group study and discussion. Once problems occur in the learning process, teachers can guide them in time. In the teaching process of flipped classroom, teachers are no longer knowledge imparters, and the traditional cramming education form is practically changed. Besides, students' independent study ability can improve. Teachers must give full play to their guiding value and let college students and teachers exchange more frequently. In this way, classroom teaching can be finished through mutual cooperation and teaching atmosphere becomes more harmonious.

Secondly, student role change is achieved. The status of learners in classroom teaching is changed. Independent study ability of college students becomes one of main assessment standards of comprehensive quality. The flipped classroom is exactly a teaching mode where college students are the subject. Through innovation of teaching mode and content, college students can overall understand key and difficult points according to their own features. Learners should apply network resources to learn overall under new media environment so as to have an all-round understanding of knowledge. It is required to pay great attention to cultivation of students' personal thinking mode in classroom teaching. College students can improve their thinking mode through learning. Teamwork ability should be practically improved through communication and changes among college students. In traditional English teaching, students completely receive knowledge passively. But in the flipped classroom, students can actively share what they have learned. Thus, flipped classroom is a knowledge hierarchy established by taking learners as the subject. It plays a great role in improving learners' ability and quality. College English teaching has very high requirements for practice, so it is very suitable for introduction of flipped teaching.

Thirdly, teaching form change is achieved. Previous classroom teaching mainly depends on teachers' explanation, and corresponding arrangements are arranged according to the key content. Thus, learners can only follow teachers to complete assignments. After-class assignment completion process is also the process of knowledge digestion, i.e. knowledge internalization process. The teaching process of flipped classroom is exactly the process of thinking with doubts. Thus, thinking difficult can extend. It is required to internalize all kinds of knowledge with pertinence in the flipped classroom. For the knowledge which cannot be fully understood, students can cooperate and discuss.

\section{Necessity of implementing flipped classroom teaching for College English under new media environment}

Application of new media content in flipped classroom of College English can well solve the practical problem that college English teaching period continues to decline. Students and teachers can apply flipped classroom as the important extension of routine English teaching so as to overall cover input materials and language output links. The application of new media resource and especially mobile learning can effectively break through time and space limit of previous teaching and overall enrich extracurricular learning content of college students. Besides, strong technical support can be provided in terms of environment, place and resource. College students can acquire information in time via new media terminals, and thus get rid of time and place limit of learning. The flipped classroom can transform classroom to the place of collaborative learning and problem solving through knowledge imparting and internalization so as to drive improvement of traditional teaching mode. Compared with previous classroom teaching, interaction and exchange between students and 
teachers in the flipped classroom become very frequent, and practical learning opportunity of college students can increase. Then, learning participation of college students can improve. These more contribute to improvement of their learning ability. Of course, English foundation of college students also differs, and the majors they learn are also different. The learning demand and progress for English course also differ. This mode is free from time and space limit, and is very beneficial for college students to learn according to their actual conditions. Thus, individualized demands of college students can be better met. In view of this, it is very necessary to introduce flipped classroom in college English teaching. It is an important way for teaching reform.

\section{Countermeasures of flipped classroom teaching for college English under new media environment}

Firstly, exchange and conduct targeted training before class. English teachers should require college students viewing relevant teaching videos before class, which is important foundation for knowledge learning and internalization. The videos come from the videos recorded by English teachers, video resources in college learning sharing platform and high-quality resources found online. Before class, English teachers should produce relevant reaching videos as per key and difficult points of teaching as well as students' cognitive rules, and upload them in the sharing platform. The teaching videos produced by teachers are usually controlled within $10 \mathrm{~min}$, and should focus on detailed knowledge points and improve memory and understanding efficiency of college students. Nowadays, there are numerous open educational resources on internet, such as Harvard open class, Yale open class, domestic network college video open class, and open classes on Netease, Sohu and Sina, etc. English teachers can search the video resources suitable for the teaching content as the key course, and provide them for college students. English teachers should arrange pre-class learning content in accordance with the theory of Proximal Development Zone. College students should utilize ubiquitous sharing platform and arrange learning progress and method as per personal conditions so as to complete pre-class training. Of course, college students can exchange with classmates via SMS, multimedia message, microblog, WeChat and QQ, etc. After college students finish the training, the results should be fed back to them quickly in the sharing platform. In this period, college English teachers can smoothly seize the key points of classroom teaching activities. Therefore, both teachers and parents should enhance supervision of students' learning in the sharing platform, and apply smart platforms to consider video viewing time so as to fast master and solve pre-class dynamic learning of college students.

Secondly, confirm problems in classroom and implement collaborative learning. The learning sharing platform set up by English teachers owns the features of intelligence and networking, and can effectively assist network English teaching and create open English learning situation. The modern information technology of sharing platform should be utilized. Teachers should supervise and manage pre-class learning situations of college students, and overall analyze the common problems that students encounter in the targeted training. Besides, teachers should overall conclude and sort out key and difficult points based on English learning content as well as confirm the project-based independent inquiry mode. College students should independently study how to effectively internalize relevant knowledge. Collaborative learning is not just helpful for college students to understand and grasp basic knowledge of English, but also contributes to improving their creative thinking ability and enhancing communication ability among college students and between individuals and social members. College students should transform to knowledge producers from consumers. College English teachers should apply reasonable learning methods (such as brainstorming method, group discussion and role play) to mobilize students' learning initiative, and encourage them to implement independent inquiry and collaborative learning according to the problems and detailed situations of college students. English teachers should become the organizer and participant of English classroom activities, overall monitor students' independent inquiry and collaborative learning, and carry out corresponding individualized tutorship so as to improve total teaching quality. 
Thirdly, after-class achievement exchange and feedback. The achievements of college students are mainly classified into two types. Firstly, students apply speech, competition or debate methods to exhibit achievements in classroom in groups or individually. Students and each group communicate, exchange and comment to overall share learning experience. Secondly, the teacher or students publish the outstanding learning achievements in the sharing platform. Students discuss via network, and associate with relevant learning resources to continuously enrich students' knowledge. The evaluation of English teachers to students tends to be diversified, and students' emotion sand values are brought in the evaluation to establish formative and summative assessment. Meanwhile, competitiveness of college students can be cultivated.

\section{Summary}

In conclusion, the flipped classroom as a new learning mode attaches great importance to practical teaching. It advocates autonomous learning and changes the inherent role of students and teachers in classroom teaching and learning. The flipped classroom teaching as a new teaching method has gained quite ideal effect in college English classroom teaching. The flipped classroom very accords with requirements of higher education system reform, and the requirements of new media environment. The flipped classroom pays great attention to the whole process of education, and the communication between students and teachers and among students so as to improve English learning efficiency as far as possible and further promote English classroom teaching quality.

\section{References}

[1] Lu Haiyan, Feasibility analysis of application of "flipped classroom" mode based on micro-course in college English teaching, Computer-assisted Foreign Language Education, 2014 (4).

[2] Fan Wenxiang, Ma Yan, Li Kai, Qiu Bingfa, Exploration on Wechat-supported flipped classroom practice under mobile learning environment, Open Education Research, 2015 (3).

[3] Cheng Yongjun, Flipped classroom and its application in college English teaching, English Square, 2015 (4).

[4] Dou Juhua, Wen Shan, Exploration on APP-based flipped classroom teaching reform for college English, Heilongjiang Researches on Higher Education, 2015 (5).

[5] Zhang Ming, Guo Xiaoyan, Research and enlightenment of new education and teaching mode in "internet +" era - micro-course, MOOC, and flipped classroom, Computer Knowledge and Technology, 2015 (12).

[6] Zhou Yuqing, Wan Shuyu, Classroom teaching under background of “internet +" - based on analysis and thinking of MOOC, micro-course and flipped classroom, China Edu Info, 2016 (2). 